\title{
Current Knowledge of Progestin-Only Pills
}

\author{
Alvaro Monterrosa-Castro ${ }^{1 \star}$, Velia Redondo-Mendoza ${ }^{1}$, Angelica Monterrosa-Blanco ${ }^{1}$
}

\begin{abstract}
${ }^{1}$ Women's Health Research Group, School of Medicine, University of Cartagena, Cartagena, COLOMBIA
\end{abstract}
*Corresponding Author: amonterrosac@unicartagena.edu.co

Citation: Monterrosa-Castro A, Redondo-Mendoza V, Monterrosa-Blanco A. Current Knowledge of Progestin-Only Pills. Electron J Gen Med. 2021;18(6):em320. https://doi.org/10.29333/ejgm/11217

\section{ARTICLE INFO}

Received: 14 Oct. 2020

Accepted: 25 Aug. 2021

\begin{abstract}
Since the 1960s, contraceptive pills have been at the service of humanity. They are one of the innovations that have contributed the most to the changing role of women in society and to women achieving the role they play today. Combined oral contraceptives (COCs) opened up opportunities to increase knowledge about the effects of estrogens and progestins in the female organism. The overall results of this evolution were progestin-only contraceptives in general and estrogen-free oral contraceptives as progestin-only pills (POPs) in particular. To identify the position currently held by POPs, a bibliographic review was carried out in the following databases: PubMed, ScienceDirect, EBSCOhost, OvidSP, Embase, and SciELO in Spanish. POPs have evolved notably from restricted use only during breastfeeding to a broader context. The absence of estrogen in the pill currently offers more advantages than disadvantages. The recent introduction of POP containing $4.0 \mathrm{mg}$ of drospirenone, administered in a 24/4-day regimen, offers better cycle control than previous POPs, as it allows much more predictable bleedings and the same contraceptive efficacy as COCs. Hormonal contraception use continues to grow. The options to regulate reproduction are numerous, and users have a greater number of options to choose the one that suits their needs and comforts. Health professionals must provide high-quality contraceptive counseling, offering all available tools, including POPs.
\end{abstract}

Keywords: oral contraceptives, progestins, progestogens, progestin-only pills, contraceptive effectiveness

\section{INTRODUCTION}

It is well-known that the predominance of estrogens in the bloodstream makes cervical mucus fluid clear, transparent, thin and acellular, conditions that facilitate viability and migration of sperm into the female reproductive tract. In contrast, the predominance of progesterone or progestins decreases the amount of cervical mucus, increases its cell density and viscosity, and makes it thick, dense and opaque, which makes sperm migration difficult [1,2].

Based on the above information, the following were defined: oral progestin-only contraception or estrogen-free oral contraception, also called progestin-only pills (POPs), or more commonly the minipill, due to the low hormone dose they provide. They differ from combined oral contraceptives (COCS) because they are estrogen-free and have a lower concentration of progestins. The absence of estrogen within the planning method can be attractive in terms of safety and the lower risk of some complications, making it a valuable alternative for family planning. However, there are demands regarding efficiency, cycle control, and user comfort [2].

Despite the many advances that have emerged with POPs in recent decades, they are not as well-understood and their use is not as widespread. Only $0.4 \%$ of all reproductive-age women in the United States use them [3]. It is necessary to specify the current framework of POPs within the wide range of family planning methods, and this was the objective of this narrative review.

\section{METHODOLOGY}

Bibliographic research with a review of clinical studies, epidemiological studies, systematic reviews, consensuses, expert meetings, meta-analyses, books, guides, and protocols, in English and Spanish. Type of participants: published articles on POPs. The research strategy was as follows: An electronic search was conducted in the PubMed, ScienceDirect, EBSCOhost, OvidSP, Embase, and SciELO in Spanish databases, between 2000 and 2018. A total of 1754 titles were identified, $433(24.6 \%)$ of which were repeat publications; therefore, 1321 were chosen. The summaries of all of them were obtained, and two rounds of reading were performed; 789 $(59.7 \%)$ had content that was subjectively considered not to fit the objective of the review and were discarded. Therefore, 532 summaries were taken into consideration. From them, the fulltext articles were obtained for 310 (58.2\%). They were reviewed, and without further qualification or measurement of the quality of the documents, $36(11.6 \%)$ were discarded because they did not have enough information on POPs; therefore, 274 documents were selected. Using snowball sampling, another 17 complete articles were chosen, and through the Google Scholar electronic alert system, another five were obtained from January to December 2018 with the term "progestogen-only pills". In addition, two articles with results of phase III studies on POP containing drospirenone, a thematic review published in 2019 and one publication with information for marketing that was published in February 2020, 
were identified. The review was carried out on 300 documents. The relevant contents were hosted in a data table specially created in Microsoft Excel. The most representative texts were included in the list of bibliographic references.

\section{BACKGROUND}

A small dose of progestin administered daily without a hormone-free interval acts by altering the biophysical characteristics of cervical mucus, which becomes a barrier that prevents sperm from ascending to the cervical canal and uterine cavity. This is the main mechanism of action of POPs [2]. Moreover, in vitro studies have shown that sperm motility deteriorates [1]. However, it is important to note that the effect on sperm penetration capacity in the cervical mucus is shortlived and decreases greatly after 24 hours of the last ingested tablet $[1,4,5]$.

The second mechanism of action of POPs is by decreasing cilia motility and the muscle contractile force of the fallopian tubes $[4,5]$. Both the effects on cervical mucus and on the fallopian tubes slow the movement of gametes through the internal genital tract, preventing fertilization, which is the primary objective of POPs [1].

Without being their main mechanism of action, POPs lower the peaks of luteinizing hormone ( $\mathrm{LH}$ ) and follicle-stimulating hormone $(\mathrm{FSH})$ in the middle of the cycle, altering the menstrual cycle. Traditional POPs (i.e., norethisterone, norethindrone, ethynodiol diacetate, lynestrenol, norgestrel, levonorgestrel) only inhibit ovulation in $50-70 \%$ of users, unlike POPs containing desogestrel or drospirenone, which are much more effective in this regard [4,6]. These POPs inhibit ovulation by negative feedback from $\mathrm{LH}$, which improves contraceptive effectiveness [1].

Although all POPs alter endometrial receptivity, this is not considered a mechanism of action since they fundamentally prevent fertilization. The endometrium becomes secretory, thin and even atrophic, which are unfavorable conditions for the implantation of the fertilized egg [1]. In addition, with the continued use of progestin throughout the menstrual cycle, there is poor biological and functional conformation of the corpus luteum, which affects the morphology of the endometrium and intracrine or endocrine signals related to implantation [5]. POPs create an inhospitable uterine environment for sperm and ovules; similar to COCs, they do not interrupt pregnancy and do not cause abortions or birth defects [7].

With perfect use of POPs, the failure rate in the first year is $0.3-0.5 \%$; however, it is estimated that the typical failure rate is closer to $5.0-9.0 \%$ due to missed or late intake of pills, a proportion similar to that offered by COCs [1]. Therefore, to get closer to perfection, the prescription of traditional POPs requires the recommendation of strict schedule adherence, and if there is a delay of three or more hours, it is mandatory to use backup contraceptive measures [5,6]. In contrast, POPs containing desogestrel or drospirenone, which offer ovulation inhibition, allow a longer delay in administration without causing a decrease in contraceptive effectiveness; however, strict schedule adherence should also be indicated [8]. Of all the available POPs, the most effective seem to be those containing desogestrel and levonorgestrel [1]. For users who forget to take the tablets frequently, it is better to suggest other less demanding methods with regard to the punctuality of administration.

POPs tend to cause simple ovarian cysts, which are actually persistent immature follicles. Approximately $50 \%$ of POP users will present them; they usually reach between four and ten centimeters in diameter and involute spontaneously after a few weeks. They offer no risk, do not merit medical treatment or surgical interventions and are not cause for suspending POPs [1]. They rarely become symptomatic or reach large sizes, but if this occurs, it is recommended that POP use be suspended and that a different method than those involving progestin alone be used [5]. A personal history of functional ovarian cysts is not a sufficient reason to contraindicate the use of POPs [1].

All POPs are safe during breastfeeding. They do not reduce milk production, and only a reduced amount of progestin is present in it, without generating a negative effect on the growth or development of the infant $[9,10]$. No modification has been observed in weight gain, arm circumference, or in the development of auditory, motor or language skills. It is recommended that POPs are started at the sixth week postpartum, although there have been no adverse effects in infants who have been exposed at an earlier age [11]. The reason for waiting until the sixth week postpartum in breastfeeding women is that there is a natural contraceptive effect from exclusive or almost exclusive breastfeeding, i.e., amenorrhea. The MELA family planning strategy (breastfeeding and amenorrhea method) that offers protection in the first weeks postpartum is indicated if there is exclusive breastfeeding plus amenorrhea. POPs have an important place in postpartum contraception in breastfeeding women, who have endocrinological conditions that increase their contraceptive effectiveness [5], although the contraceptive effect is likely to be mediated through local actions in the cervical mucus, similar to what happens in women who menstruate [12].

The lengthening of the intergenic period has shown benefits for the health of women and their children; therefore, contraception is necessary after childbirth and its onset should be in a timely manner. The contraceptive method used must be consistent with the medical history, anatomical factors, hormonal aspects, breastfeeding, and woman's preference. The availability and use of reversible contraceptive methods immediately after delivery are tools to reduce the rate of unwanted pregnancies [9,13].

POPs generally decrease the pregnancy rate, but in cases of failure, approximately $10 \%$ are extrauterine, a situation that has been linked to altered motility of the fallopian tube cilia [5]. Some authors have pointed out that POPs are more effective in preventing intrauterine pregnancies than extrauterine pregnancies, while others indicate that the incidence of ectopic pregnancy with POP use is similar to that with the use of other methods (0.095/100 women/year) [14]. However, ectopic pregnancy should always be considered and ruled out if pregnancy occurs as a result of failure of POPs. According to the Canadian Contraception Consensus, this is a grade III-A recommendation [1].

That there is a delay or decrease in fertility when suspending POPs is an unfounded belief that lacks scientific support. It has been emphasized that women who used POPs have the same chances of pregnancy as fertile couples who never used them, $25 \%$ in the first month of unprotected 
intercourse, $60 \%$ after six months, $90 \%$ after the first year and $95 \%$ in the first two years $[13,15]$.

As POPs are administered daily without a hormone-free interval and without estrogen to stabilize the endometrium, there is no hormonal suppression, and there is no programmed cyclic bleeding, so bleeding or spotting are unpredictable. They become the main adverse effect and the main cause of abandonment of the method $[1,16]$. The duration and volume of blood flow, as well as the length of the cycles, usually vary widely. Twenty percent of POP users have amenorrhea or infrequent menstrual periods, $44 \%$ have normal cycles, and 14 $30 \%$ have short cycles. Compared with COC users, POP users have more bleeding/spotting days that require protection but fewer days of spotting (very poor spotting that does not require protection); many do not have spotting at all [1]. In the event of bleeding episodes, no medical intervention is necessary, and the client must be reassured; offering counseling is the best strategy [5]. This is consistent with Abdel-Aleem et al. [17], who, after a systematic review, pointed out that several regimens have been indicated to treat or regulate bleeding due to all progestin-only contraceptives. While some regimens may be promising, none have achieved enough results to be routinely recommended.

Due to the effects on cervical mucus and the endometrium that prevent or minimize bacterial ascent through the genital tract, it has been reported that POPs probably exert a protective effect against pelvic inflammatory disease [5]. POPs do not prevent infections of the low reproductive tract. It is unknown if they interact with the human papillomavirus; they do not exert protection against the human immunodeficiency virus (HIV) or against other sexually transmitted diseases. The correct use of the male condom is suggested to prevent these entities [1]. In addition, since progestins cause stabilization of the red blood cell membrane, it is expected that women with sickle cell anemia experience fewer hemolytic crises. This favorable effect is debated, and there is still insufficient evidence to indicate it as an important benefit [18].

POPs exert a continuous effect on the endometrium, acting as good inhibitors of endometrial proliferation, an action that favors secretory changes and potentially reduces the rate of endometrial cancer. Although it has been pointed out previously, there is not enough evidence to show a protective effect against ovarian cancer. It appears that POPs have no impact on the risk of cervical, hepatic or colorectal cancer [15]. Studies in cases of inadvertent administration of POPs in pregnant women or failure of the method have not indicated that there is a harmful effect on the fetus [13]. A meta-analysis found that POPs do not increase the risk of myocardial infarction [19].

Samson et al. [20], through a systematic review, noted that POPs do not increase the risk of breast cancer, although there are few studies. In a paired case-control study, Marchbanks et al. [21] examined the risk of breast cancer among women aged 35-64 years old. They found that POPs were not associated with elevated breast cancer risk among current or former users compared to those who never used them. Any current or previous use, duration of use, age at first use and interval since last use did not alter the risk. In turn, Kumle et al. [22], in a prospective cohort study conducted in Norway and Sweden, found that regardless of duration, there was no statistically significant association between the use of POPs and breast cancer compared to never users. When women were grouped according to the age of onset of POP use, $30-39$ and $40-49$ years old, compared with never users, had RR: 1.7 [95\% Cl: 0.8-3.7] and RR: 1.6 [95\% Cl: 0.9-2.6], respectively. In another cohort study, Fabre et al. [23] found no significant association between POPs and breast cancer risk compared to never users, RR: 1.01 [95\% Cl: 0.93-1.11], and with use for less than 4.5 years, RR: 1.09 [95\% Cl: 0.92-1.29]. However, they found a significant increase with use for longer than 4.5 years, RR: 1.44 [95\% Cl: 1.03-2.00]. With each additional year of use, the risk increased, RR: 1.03 [95\% Cl: $1.01-1.06]$.

POPs can be used by users with pathologies or conditions that prevent estrogen administration [2,16], although traditional POPs should be limited, specially to breastfeeding women [24]. In this regard, the Canadian Contraception Consensus states that due to the labeling and prescription of classes, POPs are used largely during postpartum and breastfeeding. However, most women can use POPs at any point during their reproductive years [1]. We note that it should be the desogestrel POP, which inhibits ovulation, has a higher contraceptive effectiveness rate, and is the preferred POP for nonbreastfeeding women [10].

As a result of the extremely low concentration of progestin, there is a low frequency of the following side effects: nausea, vomiting, headache, breast strain, dizziness, abdominal pain, tiredness, decreased libido, fatigue, increased appetite and weight gain [1]. All these manifestations are usually very mild or temporary and are less than $10 \%$ of the causes of POP abandonment [5]. Lopez et al. [25] noted in a systematic review that the evidence is limited when assessing weight gain with the use of POPs. They found an average gain of less than two kilograms in most of the twelve-month studies. The weight change for the POP group generally did not differ significantly from that of the comparison group that used another contraceptive. In addition, they indicated that two studies that evaluated body composition showed that POP users had a greater increase in body fat and a decrease in lean body mass compared to users of nonhormonal methods. Proper advice on variations in weight can help reduce contraceptive interruption due to incorrect perceptions. Obese women may have limitations in using COCs but not POPs [25].

POPs are a good choice in patients with intolerance to estrogen preparations, which manifests as gastrointestinal problems, headache or mastalgia. They are a good resource when estrogens are relatively or absolutely contraindicated, as in the case of the following: arterial hypertension, dyslipidemia, hypertriglyceridemia, blood hypercoagulability, diabetes, cardiovascular disease, venous disease, thrombotic or embolic disease, systemic lupus erythematosus, complicated migraine headaches or related to severe neurological disorders. Additionally, POPs are very useful for women transitioning to menopause and smokers, specially if they are over 35 years of age, and for selected cases with a personal history of thrombosis [3,16]. However, Hall et al. [3] noted that few women with an increased risk of thromboembolism consider POPs when choosing oral contraception. In turn, Le Moigne et al. [26] argue, based on a cohort study, that their results reinforce current guidelines that recommend the prescription of POPs or levonorgestrelreleasing intrauterine systems in women who have had a first venous thromboembolic event. It has also been noted that POPs do not increase cardiovascular risk, do not facilitate the development of thrombosis, do not cause migraines, do not alter libido or cause weight gain [3]. 
Table 1. Progestin-Only Pills (POP) classification according to progestins

\begin{tabular}{ccc}
\hline \multirow{2}{*}{ Groups } & Progestins & $\begin{array}{c}\text { Concentration } \\
\text { per-Tablet }\end{array}$ \\
\hline Continuous administration without pause days \\
\hline & Norethisterone & $0.350 \mathrm{mg}$ \\
& $0.500 \mathrm{mg}$ \\
POP containing traditional & $0.600 \mathrm{mg}$ \\
\cline { 2 - 3 } progestins & Norethindrone & $0.350 \mathrm{mg}$ \\
\cline { 2 - 3 } & Ethinodiol diacetate & $0.500 \mathrm{mg}$ \\
\cline { 2 - 3 } & Lynestrenol & $0.500 \mathrm{mg}$ \\
\cline { 2 - 3 } & Norgestrel & $0.075 \mathrm{mg}$ \\
\cline { 2 - 3 } & Levonorgestrel & $0.030 \mathrm{mg}$ \\
\hline POP containing desogestrel & Desogestrel & $0.075 \mathrm{mg}$ \\
\hline Continuous administration for 24 days and 4 pause days \\
\hline POP containing drospirenone & Drospirenone \\
\hline \multicolumn{2}{c}{ Source: elaborated by the authors } \\
\hline
\end{tabular}

Drug interactions with POPs are less known than those with COCs [1]. As progestins are metabolized through the cytochrome $\mathrm{P} 450$ pathway, drugs that induce this pathway can lead to greater elimination of the drug and reduce contraceptive effectiveness. Concurrent use of POPs should be avoided with barbiturates, carbamazepine, oxcarbazepine, phenytoin, primidone, topiramate, bosentan, St. John's wort, rifampin/rifabutin, selective progesterone receptor modulators and protease inhibitors (i.e., darunavir/ritonavir, fosamprenavir/ritonavir, lopinavir/ritonavir, and nelfinavir) $[27,28]$. Regarding this group of drugs, a study showed a reduction in the clearance of POP containing norethindrone with an increase in the area under the curve in women with HIV who simultaneously used protease inhibitors [29]; however, in another more recent study [30], the cervical mucus score was compared in women who used POP containing $0.35 \mathrm{mg}$ of norethindrone with and without protease inhibitors. HIVpositive women who simultaneously used protease inhibitors had thickened cervical mucus, similar to HIV-positive women who did not take protease inhibitors. These results may suggest that there are no differences in the contraceptive efficacy of POPs in HIV-positive women who take protease inhibitors.

Table 1 presents the different progestins approved as POPs. Traditional POPs remain relevant in today's practice and are available in many countries. Punctual administration is required, and they are mainly indicated as oral contraception during breastfeeding. POP containing desogestrel offers a breakthrough in efficacy and allows the opportunity to administer POPs outside breastfeeding. It maintains poor cycle control like previous POPs. POP containing drospirenone increases women's comfort by providing better cycle control, preserving the possibility to be administered outside of breastfeeding and offering the effectiveness of traditional POPs. In this review, a greater emphasis is placed on POPs containing desogestrel or drospirenone for the advantages they offer compared to traditional POPs $[1,3,5]$. By the end of 2017, a package with 28 tablets of dienogest $2 \mathrm{mg}$ was introduced in many countries for the treatment of pelvic pain associated with endometriosis, but it is not approved for use as a contraceptive. Although studies have shown that it inhibits ovulation, the use of a reliable nonhormonal contraceptive method is recommended in women who use it [1].

\section{TRADITIONAL POPS}

POPs containing norethisterone, norethindrone, ethynodiol diacetate, lynestrenol, norgestrel or levonorgestrel are grouped under the term of traditional POPs; they are used worldwide, and all of them have a place in current hormonal contraception guidelines. They offer similar expectations in contraceptive effectiveness and cycle control, have low inhibitory capacity over ovulation and are preferably prescribed during breastfeeding. As they are administered daily and without pause, their main mechanism is to affect cervical mucus and endometrial histology. In this tissue, they induce underdeveloped glands without the edematous intermediate stroma that characterizes the normal secretory phase. With prolonged administration of POPs, the glands become small and scarce, they lose their tortuousness, and the walls of the blood vessels become thinner. After three months of use of POP containing norethindrone, repressed endometrial proliferation, irregular secretory changes, and areas of endometrial atrophy are observed, while with POP containing desogestrel, which is not a traditional POP, these changes are observed at six weeks. The differences observed between the two progestins are because desogestrel highly suppresses ovulation, which is not performed by any of the traditional POPs [31].

Traditional POPs offer a high level of safety, few side effects, poor cycle control and therefore a high rate of irregular bleeding. They are found to have good contraceptive effectiveness during breastfeeding but a poor Pearl Index outside of breastfeeding: 1.17 (0.7 to 3.0 according to the studies), which is high and unacceptable when compared with that observed with COCs. A Pearl Index of 2.1 has been estimated for nonbreastfeeding women aged 25-29 with traditional POPs, a much higher value than the one offered by COCs, which is why they are not recommended for this age group. This is unlike the Pearl Index of 0.3 observed in people over 40 years, which is adequate and favorable [32].

A woman's age and body weight, the presence of conditions causing intestinal malabsorption, pharmacological interactions and failure to take the pill are factors that may affect the contraceptive effectiveness of POPs. From a general point of view, the probability of pregnancy with the correct use of levonorgestrel POP is $0.5 \%$, which is usually applied for women with a weight less than 60 kilograms. When the woman exceeds this weight, the failure rate can reach 1.3\%. The higher the body fat, the more progestin is required to achieve the same level of contraceptive effectiveness [25]. On the other hand, traditional POPs can cause acne and hirsutism, due to the androgenic effect of progestins, and because of the very low doses, they do not seem to cause weight gain $[1,25]$.

It is important to note that if the levonorgestrel POP is not taken at the same time or if a tablet is missed, the probability of failure can be $5 \%$ because the levonorgestrel half-life is approximately twenty hours. For this reason, daily and punctual taking in terms of the selected time is necessary and essential. The effect of levonorgestrel on cervical mucus begins to diminish 22 hours after a dose is administered [2]. In the case of delay or missed administration of the pill, it is recommended a barrier method also be used. These concepts apply to all other POPs in the group.

Due to the estimated Pearl Index and the need for strict schedule adherence, the levonorgestrel POP has been specially 
proposed as oral contraception during breastfeeding. At the end of breastfeeding, if a levonorgestrel POP user wishes to continue hormonal contraception, COCs, monthly injections, contraceptive vaginal patches or rings may be recommended. If the woman's wish is to use estrogen-free hormonal agents, desogestrel POP is available, as well as quarterly injections of medroxyprogesterone, subcutaneous implants, and levonorgestrel-releasing intrauterine systems. Eligibility criteria and women's preferences should always be taken into account $[13,15,32,33]$.

\section{DESOGESTREL POP}

Desogestrel, a metabolite of etonogestrel, is a potent progestin of the estrane steroid group, which is very selective and has low androgenic activity. It is rapidly absorbed in the digestive tract, and as it passes through the liver, it is transformed into the active metabolite 3-keto-desogestrel. It was studied as a POP at 30,50 and $75 \mu \mathrm{g} /$ day, and ovulation inhibition was observed with all doses and in all cycles. A dose of $75 \mu \mathrm{g}$ was preferred for clinical use because it showed the lowest degree of follicular development and the most acceptable bleeding pattern [10]. The desogestrel POP has been available since the early years of the 21 st century.

The daily administration of $75 \mu \mathrm{g}$ of desogestrel consistently inhibits ovulation without increasing adverse androgenic effects and achieves a satisfactory Pearl Index of 0.14 , similar to that achieved with COCs (0.05-0.4 according to studies). It has become an important and reliable alternative for all age women who want oral contraception, are breastfeeding or not, cannot take estrogens, do not want to gain weight, suffer from dysmenorrhea or want less menstrual bleeding [34]. In women who are not breastfeeding, the contraceptive effectiveness of POP containing desogestrel is higher than that of other POPs, and in breastfeeding women, it is $100 \%$ higher than that expected in nonbreastfeeding women [10].

With the use of POP containing desogestrel, a reduction in the LH peak, a lower production of ovarian hormones and a lower follicular development were observed. Anovulation is considered to occur in $97 \%$ of cycles, without clinical effects on lipids, carbohydrate metabolism and hemostasis [35]. In a randomized double-blind controlled study published in 1998 [35] comparing $75 \mu \mathrm{g}$ of desogestrel with $30 \mu \mathrm{g}$ of levonorgestrel, it was observed that neither preparation caused significant changes in systolic or diastolic blood pressure, body weight, body mass index or heart rate. In addition, they had similar and potentially beneficial effects on hemostasis and plasma levels of coagulation parameters such as fibrinogen and thrombin/antithrombin-III complex, without modifications in antithrombin-III and protein C. In general, they observed small changes in fibrinolysis indicators and antifibrinolytic biochemicals, in favor of lower procoagulation, which contrasts with the relative increase induced by COCs. They agreed with what was announced by other authors $[1,26,36,37]$ that no thrombotic or embolic phenomena are observed with POPs. The important conclusion of the study [35] was that POPs containing levonorgestrel and desogestrel have a favorable influence on the coagulation system and do not increase the thrombotic or embolic venous risk. Several cohort studies, cases/controls, and a meta-analysis have not demonstrated a significant increase in the risk of venous thromboembolism with POPs, which may be the contraceptive option for women with an increased risk of a thromboembolic event $[1,26]$.

In addition to the beneficial effects on venous disease, favorable data regarding arterial disease have been observed. In one study [35], both levonorgestrel and desogestrel induced a significant reduction in factor-VII activity, an independent risk factor for arterial disease. Additionally, both preparations reduced fibrinogen and PAI-I, which present a risk for arterial disease when elevated, as noted by Schindler [37].

POP containing desogestrel should always be administered at the same time; however, because of the ovulation inhibitory effect, it is expected that a delay of up to twelve hours does not affect contraceptive effectiveness since the restoration of the hypothalamic-pituitary-ovarian axis takes more time [38]. In practice, one should insist on daily and fixed time intake.

Years ago, the Collaborative Study Group on the Desogestrel-containing Progestin-only Pill published [10] the results of a multicenter study conducted on healthy nonbreastfeeding women from 44 institutions in six European countries: Germany, United Kingdom, Holland, Norway, Finland, and Sweden. It was a double-blind, comparative study of the contraceptive efficacy, acceptability and safety of POPs containing desogestrel $75 \mu \mathrm{g}$ and levonorgestrel $30 \mu \mathrm{g}$. A total of 989 participants received desogestrel, and 331 received levonorgestrel for thirteen consecutive periods of 28 days. The Pearl Index for desogestrel was 0.14, and that for levonorgestrel was 1.17, a significant difference. Desogestrel showed more pronounced suppression of the hypothalamicpituitary-ovarian axis with more consistent ovulatory inhibition, which may explain the Pearl Index reached and the difference with the other progestin. If desogestrel has a better inhibitory action on ovulation than levonorgestrel, fewer ectopic pregnancies can be expected than with levonorgestrel. In the cited study [10], ectopic pregnancy was observed with levonorgestrel and not with desogestrel. With both POPs, a relatively high proportion of alterations in the bleeding pattern were observed: amenorrhea, infrequent bleeding, frequent bleeding, and prolonged bleeding.

It has been noted for many years that by inhibiting ovulation, painful episodes related to menstruation, known as dysmenorrhea, could be improved. In addition, as progestins stimulate the decidualization of the functional layers of the endometrium, preventing their growth and maturation, a reduction in the production of prostaglandins is expected, an important event in the pathogenesis of dysmenorrhea [15]. There are studies that indicate that POP containing desogestrel can improve dysmenorrhea by a magnitude similar to that of COCs, and this is one of the noncontraceptive benefits of POPS $[15,34]$. POPs can decrease pain related to endometriosis and improve premenstrual tension [15,34].

A representative group of desogestrel POP users may have amenorrhea from the start, which can be favorable if the user feels comfortable with it and has been adequately informed. It should be emphasized that over time with the use of the desogestrel POP, there is a reduction in the amount and frequency of bleeding: amenorrhea becomes longer, spotting is less frequent, and heavy/repeated bleeding tends to be less common [1].

The desogestrel POP is a timely oral alternative [32]. There are circumstances in which COCs should not be used because of the risks or undesirable effects of estrogen such as smoking, 
vascular diseases, diabetes, lupus, coronary artery disease, congestive heart failure, risk or history of thrombosis or venous embolisms, migraine headaches or estrogen intolerance, among others [26]. In these cases, if oral hormonal contraception is desired, desogestrel POP can be fully used, regardless of whether the patient is breastfeeding [1]. Nappi et al. [39] indicated that there is preliminary evidence based on headache diaries that suggests that POP containing desogestrel has a positive effect on the course of migraine with aura or without aura in most women, reducing the number of days with migraine, the number of analgesics and the intensity of symptoms. It can also be considered for women who do not want to use estrogen or even as a first-line contraceptive method for many women, alongside COCs. POPs may be appropriate for women over 35 years of age $[1,33]$ and may also prevent postpartum bone loss $[40,41]$.

\section{DROSPIRENONE POP}

In 2002, Rosenbaum et al. [42] published a multicenter, randomized, open study evaluating drospirenone, at that time a new progestin with a different pharmacological profile. Drospirenone derives from 17 alpha-spironolactone, with properties similar to those of natural progesterone. In addition, it has antiandrogenic and antimineralocorticoid effects [43]. They evaluated the inhibition of ovulation in 48 healthy women aged 19-35 years, randomized to four groups to receive POP containing $0.5 \mathrm{mg}, 1.0 \mathrm{mg}, 2.0 \mathrm{mg}$ or $3.0 \mathrm{mg}$ of drospirenone. The inhibition of ovarian activity and ovulation was dosedependent: $36 \%$ with $0.5 \mathrm{mg}$, $25 \%$ with $1.0 \mathrm{mg}, 50 \%$ with $2.0 \mathrm{mg}$ and $91 \%$ with $3.0 \mathrm{mg}$. Ovulation occurred in $9 \%$ of those who received the three lower doses, while in those who received 3 $\mathrm{mg}$, no ovulation was present.

Later, Duijkers et al. [8] studied a new pharmaceutical presentation to administer POP containing $4.0 \mathrm{mg}$ of drospirenone, using the 24/4-day intake regimen (four days of a hormone-free interval as it has been used in COCs), to try to improve the bleeding pattern. Women with proven ovulatory cycles were randomized to two groups to receive POPs for two cycles of 28 days each. One group received POP containing desogestrel without pause between cycles, and the other group received POP containing drospirenone with four hormone-free days between cycles. Both interval schemes effectively inhibited ovulation. Follicular diameter, E2 levels, and Hoogland scores were equal, which showed efficient ovarian suppression. The permeability of cervical mucus was suppressed in both groups, and the number of days of bleeding or spotting was lower in the drospirenone group. With both schemes, ovulation did not occur before the ninth day in the postintervention cycle. POP containing drospirenone inhibited ovulation with the same efficacy as desogestrel, despite the four-day interval without hormones.

In that same year, Archer et al. [44] published the results of a prospective, multicenter, noncomparative study conducted in 41 European centers in 713 healthy women at risk of pregnancy, aged $18-45$ years. They received POP containing 4.0 $\mathrm{mg}$ of drospirenone for 24 days and 4 placebo days for thirteen months to complete 7638 follow-up cycles. The estimated global Pearl Index was 0.51 [95\% Cl 0.1053-1.4922]. The proportion of participants with bleeding of any magnitude decreased from $72.7 \%$ in the first cycle to $40 \%$ in the sixth cycle and to $32.1 \%$ in the thirteenth cycle. Unexpected bleeding decreased from $49.1 \%$ in the first cycle to $22.8 \%$ at the end of the evaluation. Heavy/prolonged bleeding also decreased from $6.5 \%$ during cycles $2-4$ to $4.2 \%$ during cycles $11-13$. No deep vein thrombosis, pulmonary embolism, hyperkalemia or any relevant changes in laboratory tests, body weight, body mass index, blood pressure or heart rate were reported. Eighty-two percent of participants considered the acceptability to be excellent/good.

Regidor et al. [36] found no disadvantageous effects on different hemostatic parameters with POP containing $4.0 \mathrm{mg}$ of drospirenone; they considered it safe in terms of blood clotting, with no effect on liver-dependent clotting factors. They note that due to its pharmacological properties, it may be a valid alternative to other POPs and even to COCs since it will not confer thromboembolic risk. The antiandrogenic and antimineralocorticoid effects may favor the reduction of some events, such as acne and weight gain, which would ultimately lead to a high level of acceptability and compliance.

One of the problems of POPs is the reduction in contraceptive effectiveness with the delay or missed intake of a pill, specially with the levonorgestrel POP, thus the need for rigorous schedules. In 2016, Duijkers et al. [4] published a study using POP containing $4.0 \mathrm{mg}$ of drospirenone in 127 healthy women for two cycles to assess whether ovulation inhibition was preserved despite four 24-hour delays. In group A, delays were scheduled on days 3, 6, 11 and 22 during the second cycle, and in group $B$, the delays were scheduled on the same days during the first cycle. The follicular diameters in the cycles of regular intake and in those of the delayed cycles were similar. The overall ovulation rate was $0.8 \%$. Only one woman from group A during the second cycle met the ovulation criteria. Despite the four-day hormone-free period and multiple intentional 24-hour delays, ovulation inhibition was maintained. POP containing $4.0 \mathrm{mg}$ of drospirenone in a $24 / 4-$ day intake regimen, unlike other POPs, offers an important window of contraceptive effectiveness despite delays or missed administration of the pill.

These studies $[4,8,36,41,44,45]$ opened doors for POP containing $4.0 \mathrm{mg}$ of drospirenone in a 24/4-day intake regimen, with contraceptive effectiveness similar to that of COCs, a good safety profile and more favorable cycle control than other POPs [46]. At the end of 2019, FDA approval was provided, including for use in dysmenorrhea management. If the initial results are confirmed in larger studies or in clinical practice, POP containing drospirenone will be an important contraceptive without estrogen, free of the greatest disadvantage of the other POPs: the high frequency of unpredictable bleeding. This manifestation explains in part why POP containing desogestrel, even with significant contraceptive effectiveness, is not widely used [8,41].

Estrogens and progestins influence bone physiology and are involved in the turnover and composition of bone mineral density. Hadji, Colli \& Regidor published a recent review on the impact of estrogen-free contraception on bone health and noted that there are differences according to the affinity of progestin to glucocorticoid, androgen and mineralocorticoid receptors. They also specified that there are differences in the levels of estradiol after the use of the different progestins: dienogest $37 \mathrm{pg} / \mathrm{ml}$, levonorgestrel $120 \mathrm{pg} / \mathrm{ml}$, etonorgestrel 90 $\mathrm{pg} / \mathrm{ml}$, DMPA $26.6 \mathrm{pg} / \mathrm{ml}, 25.6 \mathrm{pg} / \mathrm{ml}$ and $35.1 \mathrm{pg} / \mathrm{ml}$, drospirenone $48.7 \mathrm{pg} / \mathrm{ml}$ and desogestrel $54.4 \mathrm{pg} / \mathrm{ml}$. They concluded that progestin-only contraceptives that lead to an estradiol level between $30-50 \mathrm{pg} / \mathrm{ml}$ after administration do 
not appear to lead to an accelerated loss of bone mineral density [47].

The availability of this new POP that is effective, welltolerated and with a predictable bleeding pattern, is very good news and has a promising place in contraception [48]. It has begun to be promoted and used universally under the name of Drospirenone-Only Pill (DOP). As the cardiovascular risks (arterial and venous) inherent to estrogen are well known, removing estrogen from the pill has been researched for years. From a cardiovascular point of view, POPs are safer than COCs [8]. Will POP containing drospirenone in a 24/4-day intake regimen start the end of $\mathrm{COC}$ use? Only time, studies and user perception will determine this.

\section{ELIGIBILITY CRITERIA AND RECOMMENDATIONS}

Only $0.6-1.6 \%$ of women have contraindications for the use of POPs; therefore, it has been proposed that they be available without the requirement of a medical prescription [1]. The World Health Organization (WHO) published the fifth edition of the eligibility criteria for the use of family planning methods in 2015, establishing four categories [33]. The first category includes POPs that can be used freely because there is no restriction. The second category includes methods that can be used; the advantages exceed the proven or theoretical risks, and more than one follow-up might be necessary. The third category includes methods that are generally not recommended unless there are no other more appropriate methods available or the available methods are not accepted by the user. The theoretical or proven risks exceed the advantages; it is the method of last choice, and using it will require close monitoring. The fourth category includes methods that should not be used as there is an unacceptable risk to women's health if the method is ordered.

The same categorization is used by the U.S. Department of Health and Human Services Centers for Disease Control and Prevention (CDC), which in 2016 published the update of the US-MEC (US Medical Eligibility Criteria for Contraceptive Use) [49], another set of criteria for selecting birth control methods. In 2017, the same entity published the Summary Table of the medical eligibility criteria for contraceptive use [50]. This last tool, simple and graphic, should be available for healthcare professionals when prescribing planning methods.

Table 2 presents the eligibility criteria for different conditions in relation to the use of POPs according to the proposal of the WHO and CDC guidelines [33,44,49].

Table 2. Progestin-Only Pills (POP) eligibility criteria (*)

\begin{tabular}{|c|c|c|c|}
\hline Condition & Category & Condition & Category \\
\hline From menarche to 45 years old & 1 & Age over 45 years old & 1 \\
\hline Nulliparous, primiparous or multiparous & 1 & Less than six weeks postpartum and breastfeeding & 2 \\
\hline More than six weeks postpartum and breastfeeding & 1 & $\begin{array}{l}\text { From the first day of postpartum onwards without } \\
\text { breastfeeding }\end{array}$ & 1 \\
\hline From the first day of abortion of the first or second trimester & 1 & From the first day of septic abortion & 1 \\
\hline History of ectopic pregnancy & 2 & History of pelvic surgery & 1 \\
\hline Smokers of any age & 1 & Smokers of any number of cigarettes & 1 \\
\hline Obesity & 1 & Multiple risk factors for Cardiovascular disease & 2 \\
\hline History of high blood pressure & 2 & Controlled arterial hypertension & 1 \\
\hline Systolic blood pressure between $140-150 \mathrm{~mm} \mathrm{Hg}$ & 1 & Diastolic blood pressure between 90-99 mm Hg & 1 \\
\hline Systolic blood pressure greater than $160 \mathrm{~mm} \mathrm{Hg}$ & 2 & Diastolic blood pressure greater than $100 \mathrm{~mm} \mathrm{Hg}$ & 2 \\
\hline History of hypertension in pregnancy & 1 & History of deep vein thrombosis or pulmonary embolism & 2 \\
\hline Current deep vein thrombosis or pulmonary embolism & 3 & $\begin{array}{l}\text { Deep vein thrombosis or pulmonary embolism stabilized } \\
\text { with anticoagulant therapy }\end{array}$ & 2 \\
\hline Family history of deep vein thrombosis & 1 & Family history of pulmonary embolism & 1 \\
\hline $\begin{array}{l}\text { Deep vein thrombosis or pulmonary embolism and major } \\
\text { surgery with prolonged immobilization }\end{array}$ & 2 & $\begin{array}{c}\text { Deep vein thrombosis or pulmonary embolism and major } \\
\text { surgery without prolonged immobilization }\end{array}$ & 1 \\
\hline $\begin{array}{c}\text { Deep vein thrombosis or pulmonary embolism and major } \\
\text { surgery without immobilization }\end{array}$ & 1 & $\begin{array}{l}\text { Thrombogenic mutations (Leiden factor } \mathrm{V} \text {, prothrombin } \\
\text { mutation, deficiencies of protein } \mathrm{S} \text {, protein } \mathrm{C} \text { or } \\
\text { antithrombin) }\end{array}$ & 2 \\
\hline Varicose veins, superficial vein thrombophlebitis & 1 & Previous coronary disease & 2 \\
\hline Coronary disease taking POP & 3 & Previous stroke & 2 \\
\hline Stroke taking POP & 3 & $\begin{array}{l}\text { Known dyslipidemias without other known cardiovascular } \\
\text { risk factors }\end{array}$ & 2 \\
\hline Complicated or uncomplicated heart valve disease & 1 & $\begin{array}{l}\text { Systemic lupus erythematosus with positive } \\
\text { antiphospholipid antibodies }\end{array}$ & 3 \\
\hline $\begin{array}{c}\text { Systemic lupus erythematosus with severe thrombocytopenia } \\
\text { or immunosuppressive treatment }\end{array}$ & 2 & Systemic lupus erythematosus without any of the above & 2 \\
\hline History of bariatric surgery, restrictive procedures & 1 & $\begin{array}{l}\text { History of bariatric surgery, procedures that induce } \\
\text { malabsorption }\end{array}$ & 3 \\
\hline Non-migraine headaches & 1 & Migrainous headaches without aura & 1 \\
\hline Migrainous headaches without aura taking POP & 2 & Migrainous headaches with aura & 2 \\
\hline Migrainous headaches with aura taking POP & 3 & Convulsive disorders & 1 \\
\hline Depressive disorders & 1 & Endometriosis & 1 \\
\hline Benign ovarian tumors & 1 & Dysmenorrhea & 1 \\
\hline
\end{tabular}

$\left(^{\star}\right) 1=$ no restriction for prescription

$2=$ advantages outweight risks

$3=$ risks outweight advantages

4= unacceptable health risk [33, 49, 50] 
Table 2 (continued). Progestin-Only Pills (POP) eligibility criteria (*)

\begin{tabular}{|c|c|c|c|}
\hline Condition & Category & Condition & Category \\
\hline Gestational trophoblastic disease & 1 & $\begin{array}{c}\text { Cervical ectropion, cervical intraepithelial neoplasia, } \\
\text { cervical cancer }\end{array}$ & 1 \\
\hline Undiagnosed breast masses & 2 & Benign breast diseases & 1 \\
\hline History of breast cancer & 1 & Current breast cancer & 4 \\
\hline Breast cancer, five years without recurrence & 3 & Endometrial cancer & 1 \\
\hline Ovaric cancer & 1 & Myoma with or without uterine cavity distortion & 1 \\
\hline Current or previous pelvic inflammatory disease & 1 & $\begin{array}{c}\text { Sexually transmitted disease including current } \\
\text { mucopurulent cervicitis due to Chlamydia or gonococcus }\end{array}$ & 1 \\
\hline Vaginitis or bacterial vaginosis & 1 & $\begin{array}{l}\text { Other sexually transmitted diseases including HIV and } \\
\text { hepatitis }\end{array}$ & 1 \\
\hline High risk for human immunodeficiency virus & 1 & Human immunodeficiency virus in any severity state & 1 \\
\hline $\begin{array}{l}\text { Schistosomiasis, malaria, } \\
\text { tuberculosis }\end{array}$ & 1 & History of gestational diabetes & 1 \\
\hline Diabetes with or without complications & 1 & Goiter, hyperthyroidism, hypothyroidism & 1 \\
\hline Current or previous gallbladder disease & 2 & History of cholestasis related to pregnancy & 1 \\
\hline History of cholestasis related to combined oral contraceptives & 2 & Viral hepatitis (Carrier, acute, chronic) & 1 \\
\hline Compensated liver cirrhosis & 1 & Decompensated liver cirrhosis & 3 \\
\hline Hepatic focal nodular hyperplasia & 2 & Hepatic or hepatocellular adenoma & 3 \\
\hline Malignant liver tumor (Hepatoma) & 3 & Iron deficiency anemia, sickle cell anemia, thalassemia & 1 \\
\hline $\begin{array}{c}\text { Antiretroviral therapy with nucleoside reverse transcriptase } \\
\text { inhibitors [NRTIs] (Abacavir, tenofovir, zidovudine, lamivudine, } \\
\text { didanosine, emtricitabine, stavudine) }\end{array}$ & 1 & $\begin{array}{l}\text { Antiretroviral therapy with non-nucleoside reverse } \\
\text { transcriptase inhibitors [NNRTIs] (Efavirenz, nevirapine) }\end{array}$ & 2 \\
\hline $\begin{array}{l}\text { Antiretroviral therapy with non-nucleoside reverse } \\
\text { transcriptase inhibitors [NNRTIs] (Etravirine, rilpivirine) }\end{array}$ & 1 & $\begin{array}{c}\text { Antiretroviral therapy with protease inhibitors [PIs] } \\
\text { (Atazanavir reinforced with ritonavir, lopinavir reinforced } \\
\text { with ritonavir, darunavir reinforced with ritonavir, } \\
\text { ritonavir) }\end{array}$ & 2 \\
\hline $\begin{array}{l}\text { Antiretroviral therapy with integrase inhibitors } \\
\text { [INIs](Raltegravir) }\end{array}$ & 1 & $\begin{array}{l}\text { Anticonvulsant therapy with phenytoin, carbamazepine, } \\
\text { barbiturates, primidone, topiramate, oxcarbazepine }\end{array}$ & 3 \\
\hline Anticonvulsant therapy with lamotrigine & 1 & Antifungal or antiparasitic therapy & 1 \\
\hline Rifampin or rifabutin therapy & 3 & Therapy with any of the other antibiotics & 1 \\
\hline $\begin{array}{l}\text { (*) } 1=\text { no restriction for prescription } \\
2=\text { advantages outweight risks } \\
3=\text { risks outweight advantages } \\
4=\text { unacceptable health risk }[33,49,50]\end{array}$ & & & \\
\hline
\end{tabular}

Table 3 presents a list of recommendations to take into ago by Family Health International [32] and have full validity at account when prescribing POPs; some were suggested years present.

Table 3. Progestin-Only Pills (POP) General Recommendations when prescribing

\begin{tabular}{|c|c|}
\hline 1 & Before the prescription, adequate clinical evaluation should be carried out and the presence of pregnancy should be ruled out. \\
\hline 2 & If there are episodes of abnormal genital bleeding, the necessary studies should be performed and the diagnosis reached. \\
\hline & $\begin{array}{c}\text { In non-breastfeeding women with menstrual cycles, POP should be started within the first five days of menstruation and should be } \\
\text { desogestrel. The effect is immediate and no backup contraceptive is needed. }\end{array}$ \\
\hline & $\begin{array}{l}\text { If POP is started on any other day of the cycle, a condom should be used within seven days. It is possible that there is protection from the } \\
\text { second day but for safety that number of days should be use. }\end{array}$ \\
\hline 5 & Levonorgestrel POP should be used only during breastfeeding. \\
\hline & $\begin{array}{l}\text { Women with exclusive breastfeeding can begin POP after the sixth week of postpartum, since there is no ovulation before that time, in } \\
\text { general. Administering it before the sixth week increases the possible adverse hormonal influence at the start of milk production. After milk } \\
\text { production is established, POP do not interfere. }\end{array}$ \\
\hline & $\begin{array}{l}\text { If breastfeeding is not exclusive, there is an increased risk of ovulation before six weeks postpartum, it is suggested to start POP from the } \\
\text { third week. }\end{array}$ \\
\hline & $\begin{array}{l}\text { In breastfeeding, amenorrhea, absence of postpartum intercourse or if pregnancy has been ruled out, POP can be initiated at any time, } \\
\text { emphasizing support with a barrier method in the first } 48-72 \text { hours. }\end{array}$ \\
\hline 9 & POP should be taken daily and at the same time, even if you do not have intercourse frequently. \\
\hline & $\begin{array}{l}\text { If the user is breastfeeding, POP should be started at six weeks postpartum and can be any of the available progestins (norethindrone or } \\
\text { similar, levonorgestrel, desogestrel or drospirenone). }\end{array}$ \\
\hline & $\begin{array}{l}\text { If the user is not breastfeeding, has had an abortion, fetal death or neonatal death, POP can be started immediately the day after delivery or } \\
\text { abortion. Desogestrel or drospirenone is suggested. }\end{array}$ \\
\hline & $\begin{array}{l}\text { If the user is not breastfeeding, POP can be started within the first } 21 \text { days after delivery without needing an additional contraceptive } \\
\text { method. If it is started after that number of days, additional protection should be used for two or seven days, the most common is the } \\
\text { condom. }\end{array}$ \\
\hline
\end{tabular}

13 Users who are not breastfeeding can change from POP to $\mathrm{COC}^{\star}$ at any time, preferably on the first day of bleeding and without minding if it

*) Combined oral contraceptives coincides with the completion of the package.

Source: elaborated by the authors 
Table 3 (continued). Progestin-Only Pills (POP) General Recommendations when prescribing

14 If the user is not breastfeeding and wishes to change from COC to POP, she should do so after the last combined active pill. This way there will be no interruption of the contraceptive effect.

15 If the user wants to change from an injectable to POP, it should be started the day the injection should be administered.

16 If the user wants to change from intrauterine device to POP, it should be started the same day of the removal.

17 When missing a pill, the patient should take it as soon as she remembers, use barrier methods or abstinence for the next 48-72 hours. The next pill should be taken at the usual time, which may mean taking two pills in a single day. This applies if the delay exceeds six hours.

18 If the user has vomiting or diarrhea, she may lose part of the progestin received. For safety it is recommended the use of barrier methods for

48-72 hours.

If the user had sex and missed a pill, she is most likely unprotected. Therefore, she must apply emergency contraception before $72-120$

19 hours, depending on the regimen. She can continue taking the POP and if necessary, a follow-up and monitoring from the health professional.

$20 \quad$ If pregnancy occurs using POP, they should be stopped immediately, and rule out the presence of ectopic pregnancy.

$21 \quad$ POP can be stopped at any time, without the need to finalize the package.

$22 \quad$ Once POP are suspended, fertility returns very soon, within a few days.

23 Do not use POP in women who suffer from seizures and receive phenytoin, carbamazepine, primidone and phenobarbital, enzyme-inducing substances that accelerate the clearance of progestins and reduce contraceptive effectiveness.

24 POP can be used in women who suffer from seizures and receive valproic acid, which does not induce liver enzymes that accelerate the 24 clearance of progestins.

25 Some authors suggest avoiding POP in women with depressive symptoms, because progestins can make them worse, however World Health Organization considers them as category one.

$26 \quad$ Antibiotics do not decrease the effectiveness of POP, except rifampin and its derivative rifabutin.

$\left.{ }^{\star}\right)$ Combined oral contraceptives

Source: elaborated by the authors

Additionally, Table 4 provides a general guide that helps decide whether COCs or POPs should be chosen, depending on the presence of some medical conditions. It is based on the proposal made by Burkett and Hewitt [7] for adolescents;

however, it can also be considered for other age groups and complemented by the eligibility criteria of the WHO and/or the CDC.

Table 4. Selection of the type of oral contraception according to medical conditions

\begin{tabular}{|c|c|c|}
\hline Medical conditions & POP* & $\operatorname{COC}^{\star \star}$ \\
\hline Asymptomatic mitral valve prolapse & YES & YES \\
\hline Symptomatic mitral valve prolapse & YES & NO \\
\hline Mitral valve prolapse associated with smoking, history of thromboembolism or coagulation disorders & YES & NO \\
\hline Uncomplicated heart valve disease & YES & YES \\
\hline Complicated heart valve disease & YES & NO \\
\hline Arterial hypertension & YES & NO \\
\hline Hypertension limited to pregnancy/ gestational hypertension & YES & YES \\
\hline Non-controlled hypertension & YES & NO \\
\hline Multiple cardiac risk factors & YES & NO \\
\hline Congenital heart disease & YES & NO \\
\hline Acute deep vein thrombosis or pulmonary embolism & NO & NO \\
\hline Resolved deep vein thrombosis or pulmonary embolism & YES & NO \\
\hline Family history of deep vein thrombosis or pulmonary embolism & YES & YES \\
\hline Inherited thrombogenic disorders & YES & NO \\
\hline Acquired coagulation disorders & YES & NO \\
\hline Uncontrolled dyslipidemias, low-density lipoprotein greater than 160 & YES & YES \\
\hline Non-migrainous headaches & YES & YES \\
\hline Migrainous headaches without aura & YES & YES \\
\hline Migrainous headaches with aura & YES & NO \\
\hline Migrainous headaches with neurological symptoms & YES & NO \\
\hline Migraine headaches with risk factors for stroke & YES & NO \\
\hline Convulsive disorders & YES & YES \\
\hline Diabetes & YES & YES \\
\hline Diabetes with target organ damage & YES & NO \\
\hline Sickle cell anemia & YES & YES \\
\hline Acute hepatitis & NO & NO \\
\hline Chronic hepatitis & YES & NO \\
\hline Liver tumors & YES & NO \\
\hline Mild/moderate liver cirrhosis & YES & NO \\
\hline Decompensated cirrhosis & NO & NO \\
\hline Active gallbladder disease & YES & NO \\
\hline History of cholecystectomy & YES & YES \\
\hline Wilson's disease & YES & NO \\
\hline Liver transplant & YES & YES \\
\hline
\end{tabular}


The prescription of POPs, like other family planning methods, must be preceded by appropriate counseling. The health professional must place the available methods in their true dimension, with their advantages, disadvantages and side effects [41]. The user will choose the method of her preference. It is the duty and responsibility of the health professional to provide instructions, recommendations, and additional information; only in this way will contraceptive effectiveness and expected protection be provided. POPs should not be indicated in women with a lack of discipline in the rigorous use of medications. POPs are probably less effective than other sustained-release progestin-only contraceptives, including subcutaneous implants, quarterly injections or the levonorgestrel-releasing intrauterine system.

\section{CONCLUSION}

POPs have an increasingly important place in hormonal contraception methods and therefore in birth control. Throughout the years, they have become much more than minipills or pills for breastfeeding women. The availability of different progestins that, without the presence of estrogen, can offer the same contraceptive efficacy offered by COCs, even during breastfeeding, is a sensitive advance. POPs containing levonorgestrel, other androgenic progestins, and desogestrel, as well as subdermal, intrauterine or intramuscular progestins alone, have been administered continuously. For the third decade of the 21st century, POP containing drospirenone, administered in a 24/4-day regimen with pause days, is available for the first time. Promisingly, POPs are beginning to be available, offering the same contraceptive efficacy and similar cycle control as COCs, without the adverse effects, risks and adverse impact on the integrity of the user, which are disavantages of the use of contraceptives containing estrogen. "New" POPs containing desogestrel or drospirenone should be favored over older formulations. POP containing drospirenone may lead to the end of COCs if women's acceptance and menstrual cycle behavior are present, as studies suggest. New progestins, or substances with progestin action, may be available in the future as birth control options tailored to women's comfort, demands, and satisfaction.

\section{TAKE HOME MESSAGES}

- Progestin-only pills containing desogestrel or drospirenone can be used with adequate safety and good contraceptive efficacy, in both breastfeeding and nonbreastfeeding women.

- The progestin-only pill containing $4.0 \mathrm{mg}$ drospirenone in the novel 24/4 regimen holds promise for adequate menstrual cycle control, similar to that offered by combined oral contraceptives.

- Progestin-only pills offer, when compared to combined oral contraceptives, the advantage of not including estrogen among the active ingredients.

- Management of dysmenorrhea has been proposed with progestin-only pills containing desogestrel or drospirenone.

- Once the POP is suspended, fertility returns very soon, within a few days.
Author contributions: The authors jointly carried out the bibliographic search, analysis and selection of the articles, writing and approval of the final document.

Funding: The "Grupo de Investigación Salud de la Mujer" is supported by Universidad de Cartagena, Colombia, as part of consolidations plans for research groups categorized by COLCIENCIAS. Act 064-2019 and resolution 01430 of 2019 . The authors did not receive fees for the research and writing work.

Ethical statement: For the realization of the bibliographic search, as well as the preparation and writing of this article, resolution 8430 of 1993 of the Ministry of Health of the Republic of Colombia, which dictates the technical, administrative and scientific standards for health research, was taken in consideration. Bibliographic research work is classified as risk-free research.

Declaration of interest: The authors declare no conflict of interest.

Presentation as a conference paper: A partial version of the article was presented as a Conference at the IV Congress of the Latin American Federation of Gynecological Endocrinology (FLEG) and III Colombian Congress of Gynecological and Reproductive Endocrinology (ACEGYR). Cartagena Colombia, 2019.

\section{REFERENCES}

1. Black A, Guilbert E. Canadian Contraceptive Consensus. Clinical practice guideline. J Obstet Gynaecol Can. 2016;38(3):279-300. https://doi.org/10.1016/j.jogc.2015.12. 003 PMid:27106200

2. Edwards L. An update and oral contraceptive options. Formulary. 2004;39:104-21.

3. Hall KS, Trussell J, Schwarz EB. Progestin-only contraceptive pill use among women in the United States. Contraception. 2012;86:653-8. https://doi.org/10.1016/ j.contraception.2012.05.003 PMid:22682722 PMCid: PMC3440515

4. Duijkers IJM, Heger-Mahn D, Drouin D, Colli E, Skouby S. Maintenance of ovulation inhibition with a new progestogen-only pill containing drospirenone after scheduled 24-h delays in pill intake. Contraception. 2016;93(4):303-9. https://doi.org/10.1016/j.contraception. 2015.12.007 PMid:26708301

5. McCann MF, Potter LS. Progestin-only oral contraception: a comprehensive review. Contraception 1994;50(Suppl 1):S9-195. https://doi.org/10.1016/0010-7824(94)90113-9

6. Milsom I, Korver T. Ovulation incidence with oral contraceptives: a literature review. J Fam Plann Reprod Health Care. 2008;34:237-46. https://doi.org/10.1783/ 147118908786000451 PMid:18854069

7. Burkett AM, Hewitt GD. Progestin only contraceptives and their use in adolescents: clinical options and medical indications. Adolesc Med. 2005;16:553-67. https://doi.org/ 10.1016/j.admecli.2005.05.010 PMid:16183539

8. Duijkers IJ, Heger-Mahn D, Drouin D, Skouby S. A randomized study comparing the effect on ovarian activity of a progestogen-only pill (POP) containing desogestrel and a new POP containing drospirenone in a 24/4 regimen. Eur J Contracept Reprod Health Care. 2015;20(6):419-27. https://doi.org/10.3109/13625187.2015.1044082 PMid:26073333

9. Espey E, Ogburn T, Leeman L, Singh R, Schrader R. Effect of progestin vs. combined oral contraceptive pills on lactation: A double-blind randomized controlled trial. Obstet Gynecol. 2012;119(1):5-13. https://doi.org/10.1097/ AOG.0b013e31823dc015 PMid:22143258 PMCid: PMC3586805 
10. Collaborative Study Group on the Desogestrel containing progestogen only pill. A double blind study comparing the contraceptive efficacy, acceptability and safety of two progestogen only pills containing desogestrel $75 \mathrm{ug} /$ day or Levonorgestrel $30 \mathrm{ug} / \mathrm{day}$. Eur J Contracept Reprod Health Care. 1998;3(4):169-78. https://doi.org/10.3109/ 13625189809167250 PMid:10036599

11. Pieh Holder KL. Contraception and breastfeeding. Clin Obstet Gynecol. 2015;58(4):928-35. https://doi.org/10.1097 /GRF.0000000000000157 PMid:26457854

12. Perheentupa A, Critchley HOD, Illingworth PJ, McNeilly AS. Effect of progestin-only pill on pituitary- ovarian axis activity during lactation. Contraception. 2003;67:467-71. https://doi.org/10.1016/S0010-7824(03)00068-4

13. Sober S, Schreiber CA. Postpartum contraception. Clin Obstet Gynecol. 2014;57(4):763-76. https://doi.org/10.1097 /GRF.0000000000000055 PMid:25264698

14. Paltieli Y, Eibschitz I, Ziskind G, Ohel G, Silbermann M, Weichselbaum A. High progesterone levels and ciliary dysfunction possible cause of ectopic pregnancy. J Assist Reprod Genet. 2000;17:103-6. https://doi.org/10.1023/ A:1009465900824 PMid:10806589 PMCid:PMC3455158

15. Raymond E. Progestin-Only Pills. In: Hatcher RA, Trussell J, Nelson AL, Cates W, Kowal D, MS P, editors. Contraceptive technology. 20th ed. New York: Ardent Media; 2011:237-47.

16. The American college of Obstetricians and Gynecologist. Practice bulletin. Noncontraceptive uses of hormonal contraceptives. Obstet Gynecol. 2010;115(1):206-18. https://doi.org/10.1097/AOG.0b013e3181cb50b5 PMid:20027071

17. Abdel-Aleem H, d'Arcangues C, Vogelsong KM, Gaffield ML, Gülmezoglu AM. Treatment of vaginal bleeding irregularities induced by progestin only contraceptives (Review). Cochrane Database of Systematic Reviews 2013;(10): CD003449. https://doi.org/10.1002/14651858. CD003449.pub5

18. Legardy JK, Curtis KM. Progestogen-only contraceptive use among women with sickle cell anemia: a systematic review. Contraception. 2006;73:195-204. https://doi.org/10.1016/ j.contraception.2005.08.010 PMid:16413850

19. Chakhtoura Z, Canonico M, Gompel A, Scarabin PY, PluBureau G. Progestogen-only contraceptives and the risk of acute myocardial infarction: a meta-analysis. J Clin Endocrinol Metab. 2011;96:1169-74. https://doi.org/ 10.1210/jc.2010-2065 PMid:21289250

20. Samson M, Porter N, Orekoya O, Hebert JR, Adams SA, Bennett $C L$, Steck SE. Progestin and breast cancer risk: A systematic review. Breast Cancer Res Treat. 2016;155(1):312. https://doi.org/10.1007/s10549-015-3663-1 PMid: 26700034 PMCid:PMC4706804

21. Marchbanks PA, McDonald JA, Wilson HG, Folger SG, Mandel MG, Daling JR, et al. Oral Contraceptives and the risk of breast cancer. N Engl J Med. 2002;346(26):2025-32. https://doi.org/10.1056/NEJMoa013202 PMid:12087137

22. Kumle M, Weiderpass E, Braaten T, Persson I, Adami H-O, Lund $\mathrm{E}$. Use of oral contraceptives and breast cancer risk: The Norwegian-Swedish women's lifestyle and health cohort study. Cancer Epidemiol Biomark Prev Publ Am Assoc Cancer Res Cosponsored Am Soc Prev Oncol. 2002; 11(11):1375-81.
23. Fabre A, Fournier A, Mesrine S, Desreux J, Gompel A, Boutron-Ruault $\mathrm{M}-\mathrm{C}$, et al. Oral progestagens before menopause and breast cancer risk. $\mathrm{Br} \mathrm{J}$ Cancer. 200713;96(5):841-4. https://doi.org/10.1038/sj.bjc.6603618 PMid:17299388 PMCid:PMC2062495

24. Hussain SF. Progestogen only pills and high blood pressure: is there an association? A literature review. Contraception. 2004;69:89-97. https://doi.org/10.1016/ j.contraception.2003.09.002 PMid:14759612

25. Lopez LM, Edelman A, Chen M, Otterness C, Trussell J, Helmerhors FM. Progestin-only contraceptives: effects on weight. Cochrane Database Syst Rev. 2013;7:CD008815. https://doi.org/10.1002/14651858.CD008815.pub3

26. Le Moigne E, Tromeur C, Delluc A, Gouillou M, Alavi Z, Lacut K, Mottier D, Le Gal G. Risk of recurrent venous thromboembolism on progestin-only contraception: a cohort study. Haematologica. 2016;101(1):e12-e14. https://doi.org/10.3324/haematol.2015.134882 PMid:26452982 PMCid:PMC4697900

27. Tseng A, Hills-Nieminen C. Drug interactions between antiretrovirals and hormonal contraceptives. Expert Opin Drug Metab Toxicol. 2013;9:559-72. https://doi.org/10.1517 /17425255.2013.772579 PMid:23425052

28. Canadian Pharmacists Association. Norethindrone drug interactions. Ottawa, Ontario: Canadian Pharmacists Association; 2014. Available at: Norethindrone drug interactions. In Lexi-Interact [Electronic version]. Retrieved from e-Therapeutics, Canadian Pharmacists Association 2014. Dalhousie University Libraries.

29. Atrio J, Stanczyk FZ, Neely M, Cherala G, Kovacs A, Mishell DR Jr. Effect of protease inhibitors on steady-state pharmacokinetics of oral norethindrone contraception in HIV-infected women. J Acquir Immune Defic Syndr. 2014;65:72-7. https://doi.org/10.1097/QAl.0b013e3182a9 b3f1 PMid:24025339 PMCid:PMC3946363

30. Atrio J, Stek A, Vora H, Sanchez-Keeland L, Zannat F, Natavio M. The effect of protease inhibitors on the cervical mucus of HIV-positive women taking norethindrone contraception. Eur J Contracept Reprod Health Care. 2015;20:149-53. https://doi.org/10.3109/13625187.2014. 957826 PMid:25285572 PMCid:PMC4655593

31. Dinh A, Sriprasert I, Williams AR, Archer DF. A review of the endometrial histologic effects of progestins and progesterone receptor modulators in reproductive age women. Contraception. 2015;91(5):360-7. https://doi.org/ 10.1016/j.contraception.2015.01.008 PMid:25596512

32. Monterrosa A. Anticonceptivos orales combinados. Tercera Edición. Editorial Impresos Calidad. Bogotá. 2003.

33. World Health Organization. Medical eligibility criteria for contraceptive use. 5th ed. Available at: http://apps.who.int/iris/bitstream/10665/181468/1/97892 41549158_eng.pdf

34. Jeng CJ, Chuang L, Shen J. A comparison of progestogens or oral contraceptives and gonadotropin-releasing hormone agonists for the treatment of endometriosis: a systematic review. Expert Opin Pharmacother. 2014;15:767-73. https://doi.org/10.1517/14656566.2014. 888414 PMid:24588662

35. Winkler UH, Howie $\mathrm{H}$, Buhler $\mathrm{K}$, et al. A Randomized controlled double blind study of the effects on hemostasis of two progestogen only pills containing 75 ug desogestrel or 30 ug levonorgestrel. Contraception. 1998;57:385-92. https://doi.org/10.1016/S0010-7824(98)00045-6 
36. Regidor PA, Colli E, Schindler AE. Drospirenone as estrogenfree pill and hemostasis: coagulatory study results comparing a novel $4 \mathrm{mg}$ formulation in a $24+4$ cycle with desogestrel $75 \mathrm{mg}$ per day. Gynecol Endocrinol. 2016;32(9):749-51. https://doi.org/10.3109/09513590.2016. 1161743 PMid:27028425

37. Schindler AE. Differential effects of progestins on hemostasis. Maturitas. 2003;46:31-37. https://doi.org/ 10.1016/j.maturitas.2003.09.016 PMid:14670640

38. Korver T, Klipping C, Heger-Mahn D, Duijkers I, van Osta G, Dieben T. Maintenance of ovulation inhibition with the 75$\mu \mathrm{g}$ desogestrel-only contraceptive pill (Cerazette ${ }^{\circledR}$ ) after scheduled 12 -h delays in tablet intake. Contraception 2005;71:8-13. https://doi.org/10.1016/j.contraception.2004 .07 .016 PMid:15639065

39. Nappi RE, Merki-Feld GS, Terreno E, Pellegrinelli A, Viana M. Hormonal contraception in women with migraine: is progestogen-only contraception a better choice? J Headache Pain. 20131;14:66. https://doi.org/10.1186/1129. 2377-14-66 PMid:24456509 PMCid:PMC3735427

40. Costa ML, Cecatti JG, Krupa FG, Rehder PM, Sousa MH, Costa-Paiva L. Progestin-only contraception prevents bone loss in postpartum breastfeeding women. Contraception. 2012;85:374-80. https://doi.org/10.1016/j.contraception. 2011.08.015 PMid:22036473

41. Grimes DA, Lopez LM, O’Brien PA, Raymond EG. Progestinonly pills for contraception. Cochrane Database Syst Rev. 2013;11:CD007541. https://doi.org/10.1002/14651858.CD0 07541.pub3 PMid:24226383

42. Rosenbaum P, Schmidt W, Helmerhorst FM, et al. Inhibition of ovulation by a novel progestogen drospirenone alone or in combination with ethinylestradiol. Eur J Contracept Reprod Health Care. 2000;5(1):16-24. https://doi.org/ 10.1080/13625180008500376 PMid:10836659

43. Elger W, Beier S, Pollow K, Garfeld R, Qing Shi S, Hillisch A. Conception and pharmacodynamic profile of drospirenone. Steroids 2003;68:891-905. https://doi.org/ 10.1016/j.steroids.2003.08.008 PMid:14667981
44. Archer DF, Ahrendt HJ, Drouin D. Drospirenone-only oral contraceptive: results from a multicenter noncomparative trial of efficacy, safety and tolerability. Contraception. 2015;92(5):439-44. https://doi.org/10.1016/j.contracep tion.2015.07.014 PMid:26232513

45. Palacios S, Colli C, Regidor PA. Multicenter, phase III trials on the Contraceptive Efficacy, Tolerability and Safety of a New Drospirenone-Only Pill. Acta Obstet Gynecol Scand. 2019 Dec;98(12):1549-57. https://doi.org/10.1111/aogs. 13688 PMid:31321765 PMCid:PMC7186823

46. Palacios S, Colli C, Regidor PA. A Multicenter, Double-Blind, Randomized Trial on the Bleeding Profile of a Drospirenone-Only Pill $4 \mathrm{Mg}$ Over Nine Cycles in Comparison With Desogestrel $0.075 \mathrm{Mg}$. Arch Gynecol Obstet. 2019 Dec;300(6):1805-12. https://doi.org/ 10.1007/s00404-019-05340-4 PMid:31728664 PMCid: PMC7174261

47. Hadji P, Colli E, Regidor PA. Bone health in estrogen-free contraception. Osteoporos Int. 2019 Dec;30(12):2391-2400. https://doi.org/10.1007/s00198-019-05103-6 PMid:31446440 PMCid:PMC7203087

48. Anonymous. Drospirenone (Slynd) - A new progestin-only oral contraceptive. Med Lett Drugs Ther. 2020 Feb $10 ; 62(1591): 18-9$

49. U.S. Department of Health and Human Services Centers for Disease Control and Prevention. U.S. Medical Eligibility Criteria for Contraceptive Use, 2016. Morbidity and Mortality Weekly Report (MMWR). Recommendations and Reports. 2016;65(3):1-108.

50. U.S. Department of Health and Human Services Centers for Disease Control and Prevention. Tabla Resumida de los Criterios Médicos de Elegibilidad para el Uso de Anticonceptivos. Actualizada 2017. Available at: https://www.cdc.gov/reproductivehealth/contraception/p df/Summary-Chart_Spanish-Web-508_tagged.pdf 